\title{
Percent non-English Speakers
}

National Cancer Institute

\section{Source}

National Cancer Institute. Percent non-English Speakers. NCI Thesaurus. Code C53343.

The fraction of a population that does not speak English. 